\title{
High Sinterability of Planetary-Bead-Milled Barium Zirconate
}

\author{
Takaaki SaKaI, ${ }^{\mathrm{a}, *}$ Hiroshige Matsumoto, ${ }^{\mathrm{a}, \mathrm{b}, *}$ Yasuhiko Sato, Junji Hyodo, ${ }^{\mathrm{c}}$ Naoki Ito, \\ Shin-ichi HASHIMOTO, ${ }^{\mathrm{d}}$ and Tatsumi IsHIHARA ${ }^{\mathrm{b}, \mathrm{c}}$
}

\author{
a Environmental Technology Research Division, INAMORI Frontier Research Center, Kyushu University (744 \\ Motooka, Nishi-ku, Fukuoka 819-0395, Japan) \\ b Center for Future Chemistry, Kyushu University (744 Motooka, Nishi-ku, Fukuoka 819-0395, Japan) \\ c Department of Applied Chemistry, Faculty of Engineering, Kyushu University (744 Motooka, Nishi-ku, Fukuoka \\ 819-0395, Japan) \\ d Institute of Multidisciplinary Research for Advanced Materials, Tohoku University (2-1-1 Katahira, Aoba-ku, \\ Sendai 980-8577, Japan)
}

Received May 9, 2009 ; Accepted August 21, 2009

\begin{abstract}
Sintering is an important process in the preparation of solid electrolytes. Milling of the precursor powders generally increases their sinterability, and thus, an effective milling method is important to obtain dense electrolytes. In this study, we demonstrate that planetary bead milling provides nanosize precursor powders with markedly high sinterability. For $\mathrm{BaZrO}_{3}$, a proton-conducting oxide with low sinterability in its unmilled state, planetary bead milling with $0.2 \mathrm{~mm}$ beads enables a reduction in sintering temperature to $1400-1500{ }^{\circ} \mathrm{C}$, which is $300-400^{\circ} \mathrm{C}$ lower than usual. We also discuss the effect of bead milling on microstructure and conductivity.
\end{abstract}

Key Words : Planetary Bead Mill, Proton Conductor, Solid Electrolyte, Barium Zirconate, Low-Temperature Sintering

\section{Introduction}

Ceramics have a variety of features, such as magnetic properties, electrical conductivity, and dielectricity, which are useful in many applications, but often require the ceramic material to be highly dense. For example, solid ceramic electrolytes in electrochemical cells must have high relative density to separate the anode and cathode compartments in a gas-tight manner. Therefore, high sinterability is strongly desirable for such materials.

To improve sinterability, it is generally effective to decrease the particle size of the precursor powders, because the driving force in sintering is the surface energy, and powders with high specific surface area are easily sintered. For this reason, precursor powders are often ball milled or attrition milled, or alternatively subjected to wet processes such as the sol-gel method, and so on.

In this paper, we report the fine pulverization of precursor powders by wet planetary bead milling using small balls, i.e., "beads," and that the obtained powders have a high sinterability.

Acceptor-doped $\mathrm{BaZrO}_{3}$ is a well known proton-conductive perovskite-type oxide, but is characterized by poor sinterability. It is usually necessary to sinter $\mathrm{BaZrO}_{3}$ powders at $\sim 1800{ }^{\circ} \mathrm{C}$ to obtain a dense material when the powders are processed by a typical solid-state reaction method. ${ }^{1-3)}$ To decrease this high sintering temperature, researchers have introduced various sintering aids., ${ }^{1,4)}$ However, these aids mostly cause adverse effects such as decreased conductivity. As mentioned in the section above, besides the addition of sintering aids, the sintering temperature can be decreased by making $\mathrm{BaZrO}_{3}$ powders into fine powders. It has been reported that the highly dense $\mathrm{BaZrO}_{3}$ was obtained at around $1600^{\circ} \mathrm{C}$ by using fine powders obtained by spray pyrolysis of barium nitrate, zirconia nitrate and yttrium nitrate. ${ }^{5}$

In the present study, we successfully decreased the dense sintering temperature of $\mathrm{BaZrO}_{3}$ powders by about $300-400{ }^{\circ} \mathrm{C}$ using fine powders obtained by "planetary bead milling". A dense $\mathrm{BaZrO}_{3}$ material was obtained by firing at the reduced temperature of $\sim 1400$ $1500{ }^{\circ} \mathrm{C}$, as described below.

\section{Experimental}

$\mathrm{BaZr}_{0.9} \mathrm{Y}_{0.1} \mathrm{O}_{3-\alpha}$ powders were prepared by a solid-state reaction method. $\mathrm{BaCO}_{3}, \mathrm{ZrO}_{2}$, and $\mathrm{Y}_{2} \mathrm{O}_{3}$ powder $(99.9 \%$ pure) were wet-blended using ethanol and then calcined at $1250{ }^{\circ} \mathrm{C}$ for $10 \mathrm{~h}$ in air. The obtained powders were planetary-milled (using a Fritsch P-7 planetary micropulverizer) with $45 \mathrm{~mL}$ zirconia pot and $2 \mathrm{~mm} \phi$ zirconia balls at $500 \mathrm{rpm}$ for $1 \mathrm{~h}$, and then pulverized by $0.2 \mathrm{~mm} \phi$ zirconia beads at $800 \mathrm{rpm}$ for $7 \mathrm{~h}$; in the latter procedure, the pulverization was performed on a 10 min rotation at 20 min intervals to avoid overheating. Ethanol was used as dispersion media. After pulverization, the obtained slurries were separated from the beads by sieve and dried into powders using an infrared lamp. The obtained powders were sieved using a $75 \mu \mathrm{m}$ mesh, isostatically pressed into a pellet shape at $200 \mathrm{MPa}$, and fired at $1000-1750{ }^{\circ} \mathrm{C}$ for $10 \mathrm{~h}$. For comparison, $\mathrm{BaZrO}_{3}$ powders milled with $15 \mathrm{~mm} \phi$ zirconia balls in same procedure as the above mentioned (at $500 \mathrm{rpm}$ for $1 \mathrm{~h}$ followed by $800 \mathrm{rpm}$ for $7 \mathrm{~h}$, denoted as "high-speed-ballmilling") or in our usual procedure (at $300 \mathrm{rpm}$ for $1 \mathrm{~h}$, denoted as "ball-milling") were also prepared. These were also sintered at $1000-1750{ }^{\circ} \mathrm{C}$ for $10 \mathrm{~h}$. Conductivity 
measurements were performed by the DC 4 terminals method using bar-shaped samples $\left(\sim 2 \times 2 \times 10 \mathrm{~mm}^{3}\right)$.

\section{Results and discussion}

Figure 1 shows images of $\mathrm{BaZrO}_{3}$ dispersed in ethanol after milling with $2 \mathrm{~mm} \phi$ balls (Fig. 1a) and further milling with $0.2 \mathrm{~mm} \phi$ beads (Fig. 1b); the amount of powder is about $2 \mathrm{wt} \%$ in ethanol in both images. After milling with $2 \mathrm{~mm}$ balls, the slurry is at first opaque (Fig. 1a), and shortly afterward separates completely into precipitates and ethanol. In contrast, after milling with 0.2 $\mathrm{mm}$ beads, the slurry is semitransparent and does not precipitate. When a diluted slurry of the bead-milled powder is irradiated by laser, the Tyndall effect is observed (Fig. 1b), suggesting that fine powders are dispersed in the bead-milled slurry. The slurry after the high-speed-ball-milling (500 rpm for $1 \mathrm{~h}$ followed by 800 rpm for $7 \mathrm{~h}$ ) was also shown in Fig. 1c. The color of slurry was grey, suggesting high contamination from the balls and pot.

Figure 2 shows $\mathrm{X}$-ray diffraction (XRD) patterns of the bead-milled and ball-milled powders (Fig. $2 \mathrm{a}$ and $2 \mathrm{~b}$ ), of the sintered $\left(1500^{\circ} \mathrm{C}\right)$ body of the bead-milled powder (Fig. 2c) and of the high speed ball milled powders (Fig. $2 \mathrm{~d})$. By pulverization using $0.2 \mathrm{~mm} \phi$ beads, the peaks broaden without any change in the perovskite structure. From the XRD patterns, the mean particle size of the bead-milled powder calculated using the Scherrer equation is $14 \mathrm{~nm}$, indicating that bead milling finely grinds $\mathrm{BaZrO}_{3}$ into nanopowders without changing the crystal phase. However, a weak peak derived from $\mathrm{ZrO}_{2}$ also appears in the XRD pattern of the sintered body, even though the contamination peak was much weaker than that of the high-speed-ball-milled powders. This result indicates that we must deal carefully with possible contamination from the bead material into the specimen in further investigations.

Figure 3 shows the relationship between the relative density and sintering temperature for bead-milled, ballmilled $^{1)}$ and high-speed-ball-milled powders. It is noteworthy that the temperature required to obtain the same ceramic density is as much as about $300-400{ }^{\circ} \mathrm{C}$ lower for the bead-milled than for the ball-milled powder. In addition, the temperature was lower than that required for

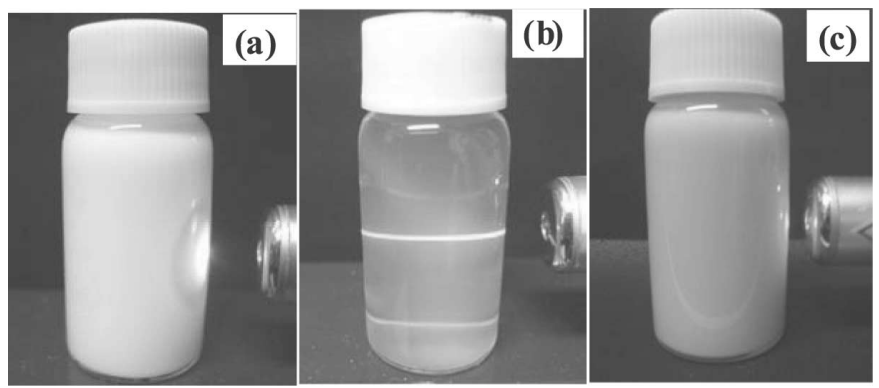

Fig. 1 Photos of slurries after milling ( $2 \mathrm{wt} \%$ slurry): (a) 2 $\mathrm{mm} \phi$ ball-milled slurry; (b) $0.2 \mathrm{~mm} \phi$ bead-milled slurry, showing the Tyndall effect; (c) $15 \mathrm{~mm} \phi$ high-speed-ballmilled slurry.

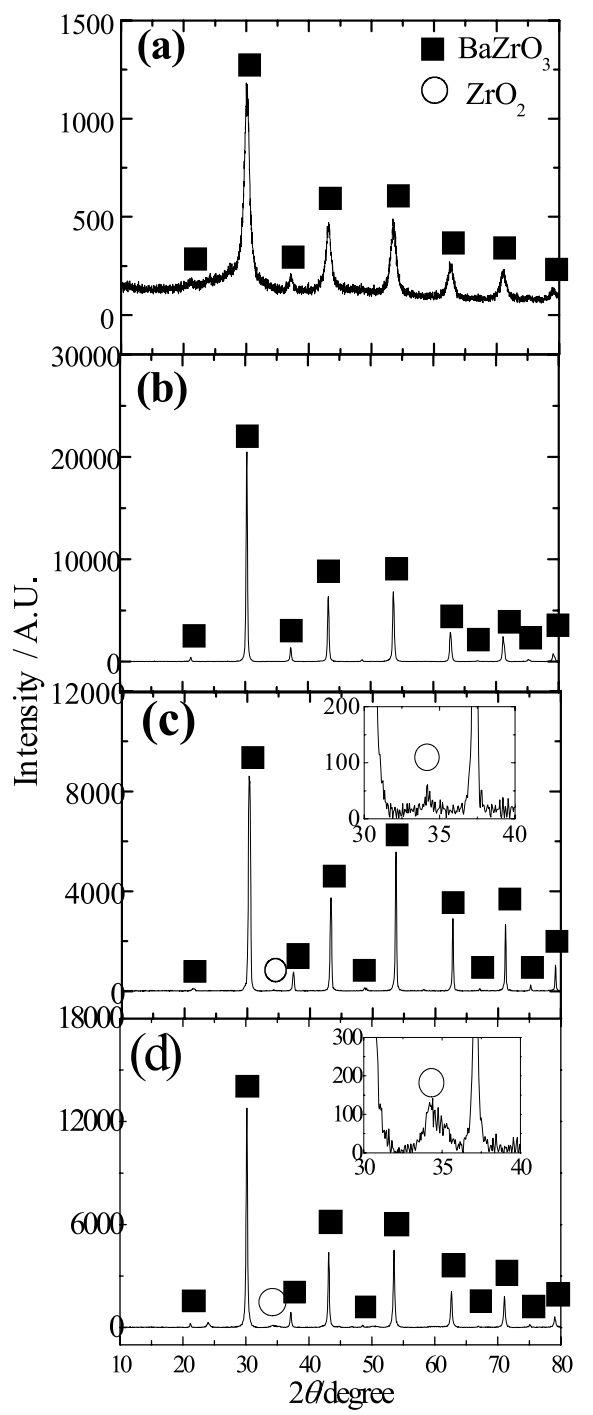

Fig. 2 XRD patterns: (a) Calcined powder, $0.2 \mathrm{~mm} \phi$ bead milled; (b) Calcined powder, $15 \mathrm{~mm} \phi$ ball milled; (c) Sintered body of $0.2 \mathrm{~mm} \phi$ bead milled powders; (d) Calcined powder, $15 \mathrm{~mm} \phi$ high-speed-ball-milled.

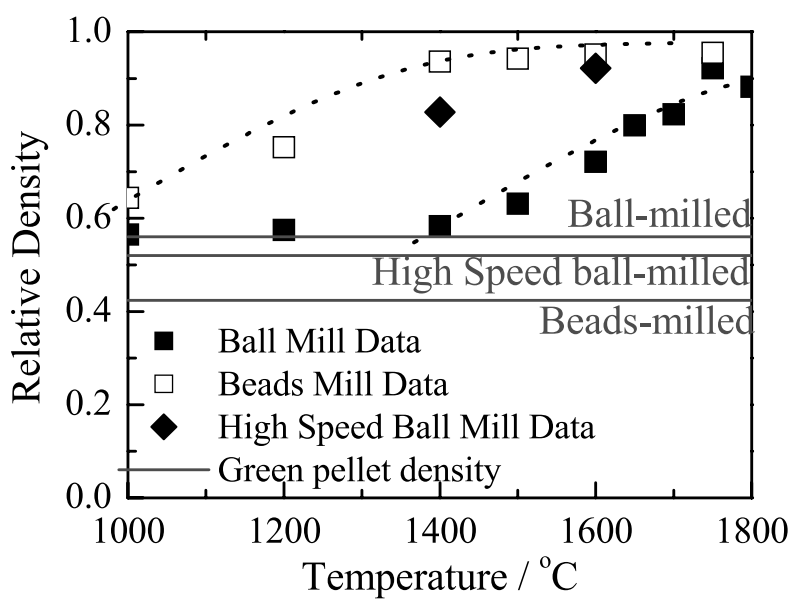

Fig. 3 Variation of relative density with sintering temperature for bead-milled, ball-milled and high-speed-ballmilled powders. 

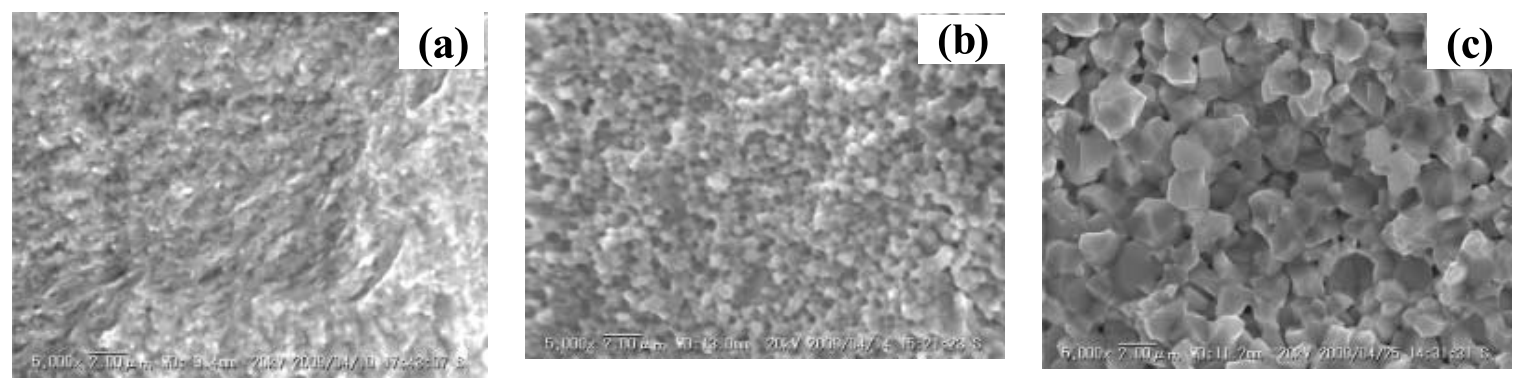

Fig. 4 SEM images of the cross section of the sintered bodies of bead-milled and ball-milled powders: (a) Bead-milled powder sintered at $1500^{\circ} \mathrm{C}$; (b) Bead-milled powder sintered at $1750{ }^{\circ} \mathrm{C}$; (c) Ball-milled powder sintered at $1750{ }^{\circ} \mathrm{C}$.
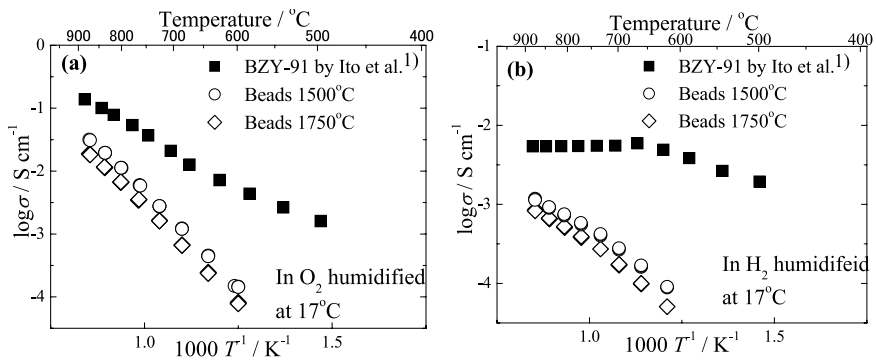

Fig. 5 Conductivity of bead-milled powders sintered at 1500 and $1750{ }^{\circ} \mathrm{C}$; (a) In $\mathrm{O}_{2}$ atmosphere humidified at $17^{\circ} \mathrm{C}$; (b) In $\mathrm{H}_{2}$ atmosphere humidified at $17^{\circ} \mathrm{C}$.

densification of the high-speed-ball-milled powders. Highly sintered $\mathrm{BaZrO}_{3}$ is obtained successfully at temperatures as low as $1400-1500{ }^{\circ} \mathrm{C}$; the relative densities are $93.6 \%$ at $1400{ }^{\circ} \mathrm{C}$ and $94.2 \%$ at $1500{ }^{\circ} \mathrm{C}$. Thus, in conclusion, bead milling provides a markedly sinterable precursor powder, reducing the sintering temperature of the poorly sintering oxide.

Figure 4 shows SEM images of hand-broken cross sections of bead-milled and ball-milled powders sintered at 1500 and $1750{ }^{\circ} \mathrm{C}$. These images clearly show that bead milling enhances the sinterability of the resulting powder, but has little effect on the following grain growth. A sample fired at $1500{ }^{\circ} \mathrm{C}$ (Fig 4a) contains no micron-size grains, whereas samples fired at $1750{ }^{\circ} \mathrm{C}$ (Fig. 4b,c) do show such grains. Grain growth is controlled by mass transfer between grains and is little affected by the initial size of the precursor. For the same firing temperature of $1750^{\circ} \mathrm{C}$, the grain size is reduced by use of bead milling in the present experiment. The reason is unclear and is under investigation, including the possible effect of $\mathrm{ZrO}_{2}$ contamination.

Figure 5 shows the conductivities of bead-milled powders sintered at 1500 and $1750{ }^{\circ} \mathrm{C}$ measured in $\mathrm{H}_{2}$ or $\mathrm{O}_{2}$ atmosphere humidified at $17^{\circ} \mathrm{C}$. For comparison, the conductivity of a ball-milled powder sintered at $1750{ }^{\circ} \mathrm{C}$ in our previous report ${ }^{1)}$ is also shown. The conductivities of both 1500 and $1750{ }^{\circ} \mathrm{C}$ bead-milled powders decrease, compared to the ball-milled powder, suggesting that the effect of grain boundary is remarkably exposed in both cases because both samples have small grain size.3) These results also indicate that bead milling is useful for obtaining small-grain samples to observe the effect of grain boundaries.

\section{Conclusion}

By the use of planetary milling with small beads, it is possible to enhance the sinterability of ceramics and obtain a dense sintered body of high-sintering-resistivity materials such as $\mathrm{BaZr}_{0.9} \mathrm{Y}_{0.1} \mathrm{O}_{3-\alpha}$ at lower temperatures. This method is expected to be widely applied not only for fabrication of dense ceramic membranes but also for control of grain diameter. However, small beads are likely to cause contamination in the samples, and thus, further investigation is necessary to examine this phenomenon as well as the influences of rotation speed, bead size, milling time, and similar factors. In addition, oxide nanopowders have the potential to exhibit different functions with decreasing grain diameter, and planetary bead milling is an effective means to obtain these nanopowders.

\section{Acknowledgement}

This study was supported by Grant-in-Aid for Scientific Research (B) (21360481), from Japan Society of the Promotion of Science (JSPS).

\section{References}

1) N. Ito, H. Matsumoto, Y. Kawasaki, S. Okada, and T. Ishihara, Solid State Ionics, 179, 324 (2008).

2) K. Katahira, Y. Kohchi, T. Shimura, and H. Iwahara, Solid State Ionics, 138, 91 (2000).

3) F. Iguchi, N. Sata, T. Tsurui, and H. Yugami, Solid State Ionics, 178, 691 (2007).

4) P. Babilo and S. M. Haile, J. Am. Ceram. Soc., 88, 2362 (2005).

5) P. Babilo, T. Uda, and S. M. Haile, J. Mater. Res., 22, 1322 (2007). 